\title{
Durability Evaluation of Reinforced Concrete Arch Bridge Based on Fuzzy Analytic Hierarchy Process Method
}

\author{
Wu Fangwen*, Yang Caofang and Xue Chengfeng
}

\author{
School of Highway, Chang'an University, Xi'an, Shaanxi,710064, P.R. China
}

\begin{abstract}
Durability damages in varying degrees occur in numerous bridges during the service stage. Most problems caused by durability damages, including insufficient carrying capacity, aging, and breakage, among others, will directly threaten the safety performance of the structure and affect its normal condition. It requires field test to inspect in detail and reassess the structure, so that proper action can be taken to maintain the structure. Based on the Analytic Hierarchy Process, this study aims to establish a durability assessment model of a reinforced concrete arch bridge through membership function by combining fuzzy theory, to solve the sensitivity of different degrees of damages on assessment result by setting weight, and to conduct durability assessment of the superstructure of reinforced concrete bridges through the application of comprehensive weight variation fuzzy assessment. Results indicate that the structure is in a good state, and the durability assessment is in good agreement with the actual situation of the bridge.
\end{abstract}

Keywords: Analytic Hierarchy Process, Fuzzy assessment, Membership function, Reinforced concrete arch bridge.

\section{INTRODUCTION}

Durability of a structure is defined as the capability of such structure to complete a predetermined function within the given time under normal design, construction, application, and maintenance. In the process of construction and service, bridges are corroded by the environment and harmful chemical substances, as well as affected by vehicles, wind, earthquake, fatigue, overload, human factors, and other external effects. The material performance of bridges gradually degrades with the passage of time. Different degrees of damages occur in all parts of a bridge, which will affect the durability of this structure. Therefore, bridge evaluation is essential to maintain and retrofit efforts and has drawn much attention world-wide. Arch bridge is one important bridge style and is applied widely in civil engineering. There are a large number of reinforced concrete arch bridges in China [1, 2], and some of them were damaged or collapsed in the past decades as shown in Fig. (1). Therefore, durability assessment for existing reinforced concrete arch bridges, as well as their maintenance, has attracted researchers attention. The durability of reinforced concrete arch bridges has recently become a research topic in civil engineering. The study on the theory and application of durability assessment for reinforced concrete arch bridge can reveal the potential risk in the structure and provide the correct information to make timely decisions for repairing, reinforcing, or removing bridges to avoid severe accidents. In addition, research results can be directly applied to guide the design and repair of bridges to extend their service life and minimize repair and reinforcement costs. The current study is significantly meaningful in terms of technology and economy.

*Address correspondence to this author at the School of Highway, Chang'an University, Xi'an, Shaanxi,710064, P.R.China; Tel: +86 2982338970 ; E-mail: iBridge2014@163.com

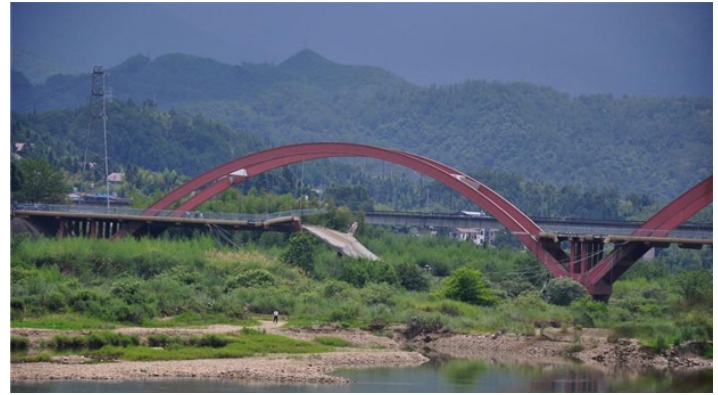

(a) Gongguan Bridge damaged in 2011



(b) Kong Que He bridge damaged in 2011

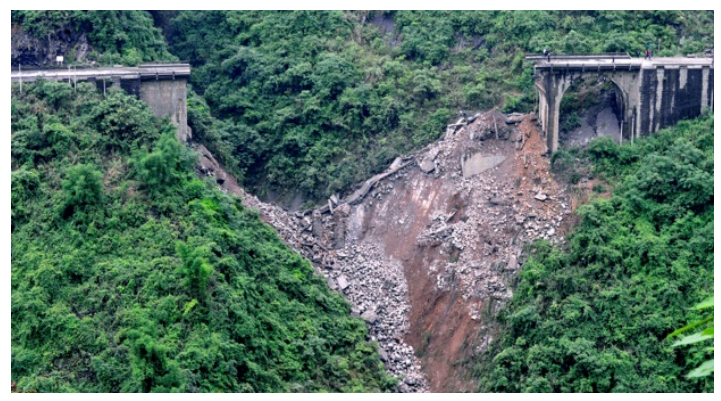

(c) Hong Ni Shi bridge damaged in 2010

Fig. (1). Arch Bridge Damage. 
Since the middle of the 1980 s, many researchers from home and abroad have extensively conducted in-depth studies on the durability evaluation of bridge structure through research stages from material to component of structures studies. Such studies have provided many assessment methods, including Probability Method, Artificial Neural Network (ANN), Analytic Hierarchy Process (AHP), Grey Associated Analysis, and Comprehensive Weight Variation Evaluation.

\subsection{Analytic Hierarchy Process (AHP)}

AHP was proposed in the mid-1970s by Professor Thomas L. Saaty of the University of Pittsburgh, USA. This process aims to divide a complicated problem into several components, which are grouped based on the dominance relationship; thus, forming an orderly hierarchical structure. The relative importance of all factors in the hierarchical structure is confirmed by means of pairwise comparison approach. Human judgment is then integrated to confirm the total order of relative importance of all factors. AHP is a form of quantitative analysis, the application of which can be divided into four steps: (1) to establish the hierarchical structure of problem; (2) to construct a pairwise judgment matrix; (3) judgment matrix is used to calculate the relative weight of the elements to be compared; and (4) to calculate the combined weights of all layers of elements.

\subsection{Artificial Neural Network (ANN)}

ANN, which is also called Neural Network, is an important branch of artificial intelligence. ANN is a kind of computing model established through abstract, simplification, and simulation of the human brain neural system from the microscopic structure and function. It can simulate partial ability of thinking in images of humans. ANN is characterized by non-linear feature, learning capability, and self-adaptability. It consists of simple information processing units called neurons. It can accept and process the information, which is accomplished through the interaction between processing units, and by expressing a problem as a connection weight between processing units.

\subsection{Fuzzy Matter-Element Analysis}

Matter-element analysis, which is a discipline involving mathematics and experimentation, was developed in 1983 by Professor Chai Wen, a Chinese scholar. Its main principle is to describe the matter by using three factors, namely, object, characteristics and value, which consist of the basic elements of the ordered triple, namely, matter element. Matter-element analysis aims to investigate matter element and its changing law, which is an effective approach to solve inconsistent real-world problems. Fuzzy matter-element analysis aims to combine fuzzy mathematics with matter element organically to analyze and integrate the fuzzy value showing the characteristics of object and the inconsistency affecting various factors; thus, obtaining a new method of solving this kind of fuzzy and inconsistent problem is needed. Zhu Pinghua combined fuzzy matter-element analysis with AHP to raise the durability assessment approach of in-service bridges based on fuzzy matter-element [3].

\subsection{Fuzzy Hierarchy Process AHP}

Professor Lotfi A. Zadeh (USA) first raised the concept of fuzzy sets in 1965. This concept provides a mathematical tool for the complicated matter, which enables comprehensive fuzzy evaluation on the complicated matter. Eventually, comprehensive fuzzy evaluation based on fuzzy sets has been widely developed. The characteristics of fuzzy evaluation facilitated its precise use in the durability assessment of bridges.

Fuzzy AHP is a kind of extended deformation of the traditional deterministic AHP. The basic concept of fuzzy set theory is to recognize the fuzzy of matter in the development process. This theory believes that the object involved in a discussion is gradually transited from belonging to a certain set to non-belonging to a certain set. This transition does not happen suddenly. The judgment is changed from judging if the object belongs to a certain set to judging the degree of membership of the object to a certain set.

Among the various methods for bridge evaluation, analytical hierarchy process is widely used [4, 5], which adopts the hierarchy models of bridge condition to analyse the structure serviceability and durability. The most important steps for the model are the optimal weight matrix and the judgment matrix. Yang fan adopted several scales in the analytical hierarchy process to build the judgment matrix, and calculated the weights for the parts of one railway concrete bridge [6]. Xu Xiao-hua used the analytical hierarchy process to generate a hierarchy structure of the factors affecting the comprehensive performance and evaluate a railway concrete bridge [7]. The bridge is composed of girder, bearing, pier, and other component, every component's safety influences the whole bridge's safety in different degree. The safety of individual components is affected by load, crack, deflection and other random factors.

The factors influencing the durability of reinforced concrete arch bridges vary, and these factors are taken randomly in fuzziness, which are difficult to measure accurately. Therefore, fuzzy AHP combined with fuzzy theory with AHP emerged. Such combination can evaluate fuzzy reaching degrees more objectively by combining quantitative and qualitative methods. It is characterized by relatively simple, suitable to multiple and complicated problems. Yang Ze-ming established a safety evaluation model of one existing reinforced concrete bridge based on analytic hierarchy process method, and combined the fuzzy synthetic method to evaluate the bridge safety [8]. Ming-Te set up an evaluation multiple layer fuzzy method model to assess the damage stage of existing reinforced concrete bridges [9]. The quantitative information obtained from field test inspections can be analyzed by probability theory, but a parallel analysis can not be developed for the qualitative information obtained to assess the structure. The fuzzy relation algorithm which makes use of the fuzzy set theory is developed to analyze the qualitative data $[10,11]$.

This paper combines fuzzy analytic hierarchy process method and field test inspection data to establish the durability evaluation model for reinforced concrete arch bridge through membership function. Durability assessment is conducted for superstructures, particularly reinforced 
concrete bridges, by means of comprehensive weight variation evaluation principle.

\section{BUILDING EVALUATION MODEL OF ARCH BRIDGE}

Durability assessment system for reinforced concrete arch bridges is complicated. Numerous factors influence the durability of a bridge in such a system. Moreover, all factors are related to one another. Therefore, to assess the durability of reinforced concrete arch bridge in a reasonable, scientific, and comprehensive manner, an assessment model is established based on the object hierarchy, as well as on AHP. A reinforced concrete arch bridge consists of a main arch, vertical (horizontal) beam, tie, boom, post, abutment, accessories, and other parts. Each major component is divided into several sub-components. Each sub-component has multiple properties, which are the underlying index. The assessment indexes have two forms, namely, qualitative and quantitative descriptions. To attain a more accurate analysis, all evaluation indexes should be presented in the quantitative form. Descriptive language variables should be quantitatively analyzed by means of fuzzy theory. Based on the aforementioned method, the evaluation system for reinforced concrete arch bridges is established in accordance with the principles of practical convenience, as shown in Fig. (2). The figure shows that the major factors that affect the durability of reinforced concrete arch bridge are steel bar corrosion, concrete crack, concrete strength, concrete damage and suspender corrosion.

\subsection{Classification of Assessment Levels}

To maintain being identical with the existing regulations and standards in China( JTG/T H21, 2011), the current study presents a level assessment on the durability of in-service reinforced concrete arch bridge by means of the classification of levels. This assessment is divided into four levels, as shown in Table $\mathbf{1}$.

\subsection{Weight Ascertainment and Variable Weight Method}

Weight issue is highly important. Comprehensive evaluation can be correctly done only with rational weight distribution. This study adopts AHP to confirm weight. However, a judgment matrix should be initially constructed before confirming the weight. A judgment matrix presents the relative importance between a particular layer and its related factor for a certain factor of the previous layer. The value of judgment matrix factor reflects evaluator understanding of the relative importance of all factors, which is generally in the proportion quotiety of 1 to 9 . Judgment matrix can be used to obtain the maximum eigenvalue $l_{\max }$

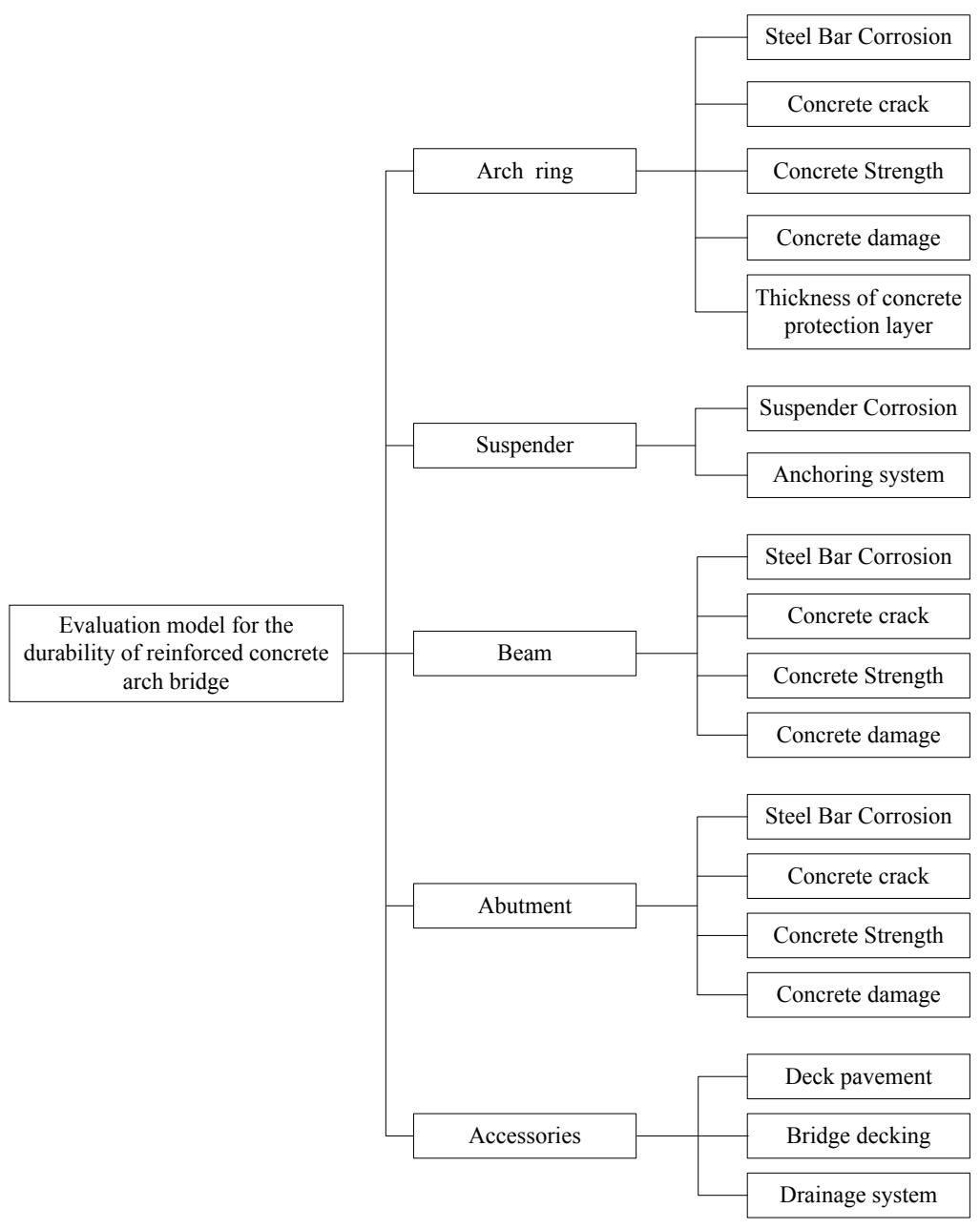

Fig. (2). Evaluation model for reinforced concrete arch bridges. 
Table 1. Assessment levels for the durability of bridge.

\begin{tabular}{|c|c|c|}
\hline Assessment Levels & Assessment Words & Suggestions in engineering management and reinforcement \\
\hline I & Good & In good condition, continue to use, with regular monitoring \\
\hline II & Ordinary & $\begin{array}{l}\text { Continue to use, to repair, and protect locally, and to enhance monitoring of the working conditions of } \\
\text { components, to make maintenance }\end{array}$ \\
\hline III & Poor & Continue to use in a short time, repair the severely damaged parts, enhance the repair \\
\hline IV & Bad & Replace, make major repair or reinforcement \\
\hline
\end{tabular}

$\lambda_{\max }$ and the corresponding eigenvector being normalized $W=\left(w_{1}, w_{2}, \mathrm{~L} \mathrm{~L}, w_{n-1}, w_{n}\right)$. This eigenvector is the required weight vector.

In consideration of the different contributions of different damage indexes to assessment result, weight variation assessment, namely, correction weight is conducted.

Suppose that the measured value of an index is $x_{i}$, and the maximum value of assessment standard is $x_{i \max }$, the information weight of this index $W_{i}$ dis

$W_{i}^{\prime}=\left(0.1+0.9 x_{i} / x_{i \max }\right)$

If the initial weight of this index is set to $W_{i}^{0}$, then the correction weight $W_{i}$ is

$W_{i}=W_{i}^{0} * W_{i} \Leftarrow W_{i}^{0}\left(0.1+0.9 x_{i} / x_{i \max }\right)$

\subsection{Index of Influencing Factor for Evaluation Model}

To understand fuzzy AHP, the concept of fuzzy set should be realized first. For clear set $A$, element $x$ does not belong to Set $A$ or does not belong to $A$. For fuzzy set $A$, in a certain universe $\mathrm{U}$, under $x \mathrm{CEU}, x$ in a certain degree $m(m \propto E(0,1))$ belongs to $A$, instead of $x$ belonging to $A$ or $x$ not belonging to $A$. This relationship is the basis of understanding fuzzy evaluation method.

Deterioration phenomena of concrete structure durability damage are concrete carbonization, steel corrosion in concrete, freeze-thaw damage, crack, concrete strength reduction, and over-deformation of the structure, among others [12]. The influencing factors on the durability of the structural layers of reinforced concrete arch bridges considered in the current study are listed in Fig. (1). Fuzzy membership functions of all factors on the durability discussed in this paper are distributed in triangle. The membership functions of all factors are listed, as shown in Figs. (3 to 7).

Quantitatively describing the index classification of the influencing factors on the durability of arch ribs, boom, and accessories of a bridge is extremely difficult. Thus, providing similar membership function is inappropriate. Based on the stipulations in the Standards for Technical Condition Evaluation of Highway Bridges (JTG/T $\mathrm{H} 21,2011$ ), the qualitative indexes are changed to the quantitative indexes by making grading standards.

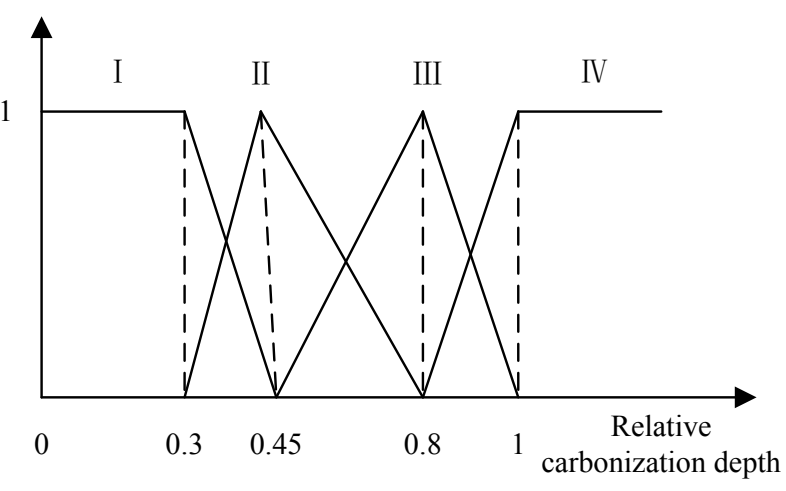

Fig. (3). Membership function for concrete relative carbonization depth.

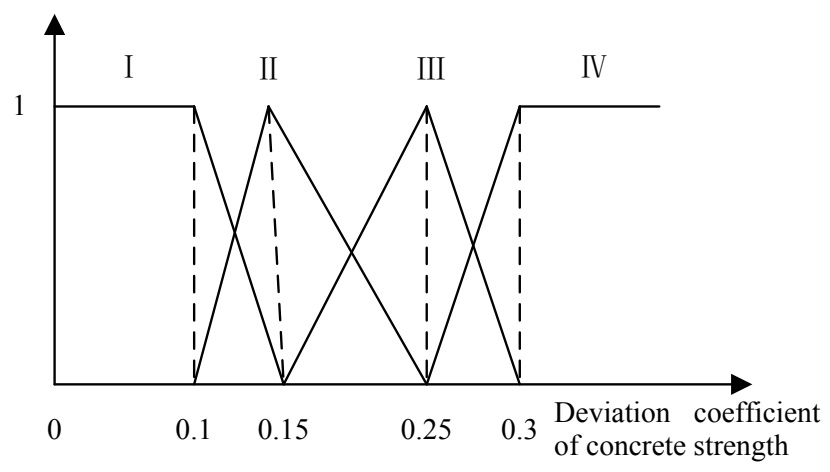

Fig. (4). Membership function for the quality grade of concrete.

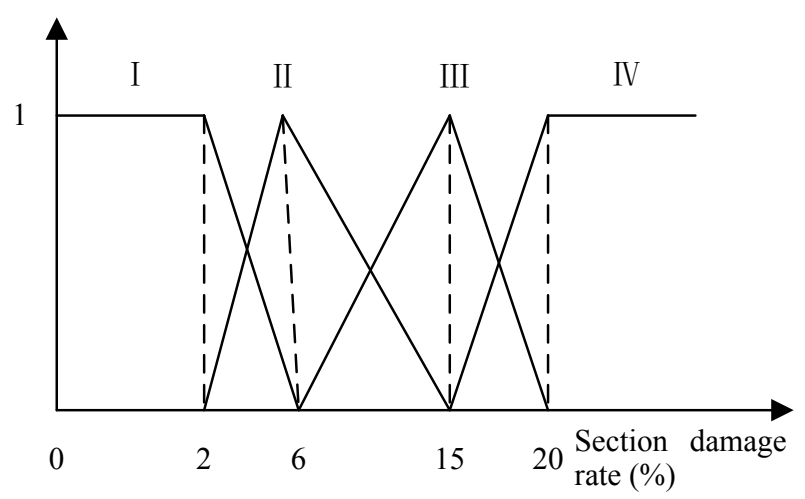

Fig. (5). Membership function of concrete damage grade. 


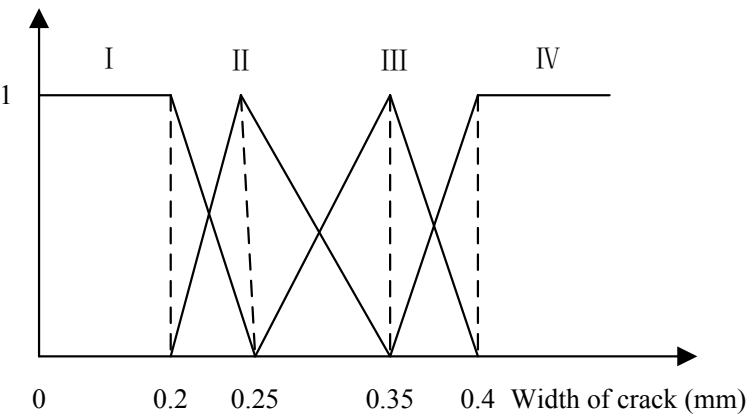

Fig. (6). Membership function of crack width grade.

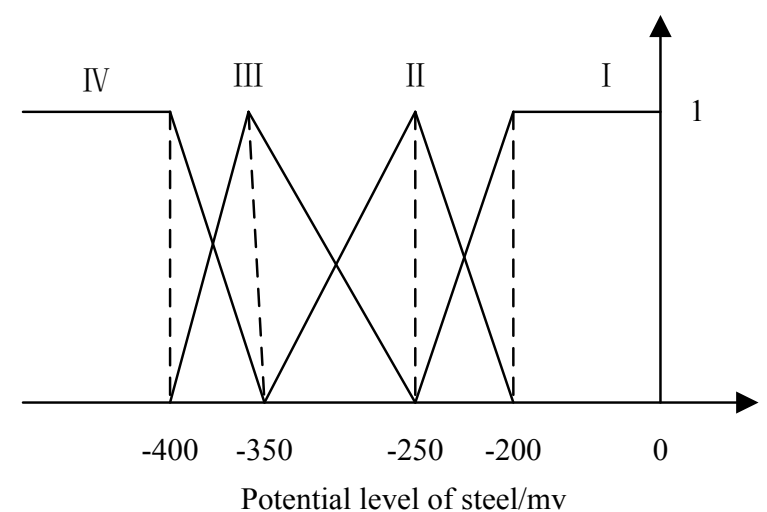

Fig. (7). Membership function of steel corrosion grade.

\subsection{Establishment of Fuzzy Assessment Relation Matrix for the Durability}

Fuzzy assessment relation matrix for the durability indexes is likewise called membership evaluation set or fuzzy converter.

Factor set of assessment index is set to: $U=\left\{u_{1}, u_{2}, u_{3}, \mathrm{~L} \mathrm{~L}, u_{n-1}, u_{n}\right\}$

Assessment set is:

$Y=\left\{y_{1}, y_{2}, y_{3}, \mathrm{~L} \mathrm{~L}, y_{m-1}, y_{m}\right\}$

where $n$ refers to the number of items in the factor set of assessment index and $m$ refers to the number of items in the assessment set. Thus, the matrix is:

$R=\left[\begin{array}{llll}r_{11} & r_{12} & \cdots & r_{1 m} \\ r_{21} & r_{22} & \cdots & r_{2 m} \\ \vdots & & \vdots & \vdots \\ r_{n 1} & r_{n 2} & \cdots & r_{n m}\end{array}\right]$

is called the fuzzy membership matrix from $\mathrm{U}$ to $\mathrm{Y}$. In $R$, element $r_{i j}$ indicates the degree of membership $i$ factor in $U$ relative to $j$ assessment.

\subsection{Fuzzy Assessment Set B}

Assessment matrix that considers the weight of each factor is investigated through fuzzy matrix synthesis. If $B$ is used to show multi-factor fuzzy assessment set matrix after being synthesized, then fuzzy set B is recorded as:

$$
B=W_{i} * R_{i}=\left(w_{1}, w_{2}, \cdots \cdots, w_{n}\right) \cdot\left[\begin{array}{llll}
r_{11} & r_{12} & \cdots & r_{1 m} \\
r_{21} & r_{22} & \cdots & r_{2 m} \\
\vdots & \vdots & \vdots & \vdots \\
r_{n 1} & r_{n 2} & \cdots & r_{n m}
\end{array}\right]=\left(\begin{array}{llll}
b_{1}, & b_{2}, & \cdots \cdots & b_{n}
\end{array}\right)
$$

where, "*" refers to the fuzzy operator, and the operation is: $b_{j}=/_{i=1}^{n}\left(a_{i} \ddot{Y} r_{i j}\right)$. This kind of operation provides prominence to the major factors in the assessment, ignoring the influence of the remaining indicators. The operation rule of the sign of operation "/ " is $a / b=\max (a, b)$, and that of " $\ddot{Y} "$ is $a \ddot{\mathrm{Y}} b=\min (a, b)$.

\section{INTRODUCTION AND APPLICATION OF THE PROJECT}

\subsection{Introduction of the Project}

Xiao Nan Men Bridge on the Jinsha River, Yibin, Sichuang Province was built in 1991. The main bridge is half-through steel composite reinforced concrete arch bridge, with a main span of $243.367 \mathrm{~m}$, vector height of $48.236 \mathrm{~m}$, and rise-span ratio of $1 / 5$. The arch axis is catenary style and the arch axis coefficient $n=1.756$. The southern and northern approaches of the bridge are reinforced concrete continuous girder bridges, spanning are $2 \mathrm{~m} \times 16 \mathrm{~m}$ and $6 \mathrm{~m} \times 16 \mathrm{~m}$, respectively. The full length of the bridge is $387.37 \mathrm{~m}$, as shown in Fig. (8). In 2001, Xiao nan men Bridge was reinforced and repaired again after it collapsed because of suspender.

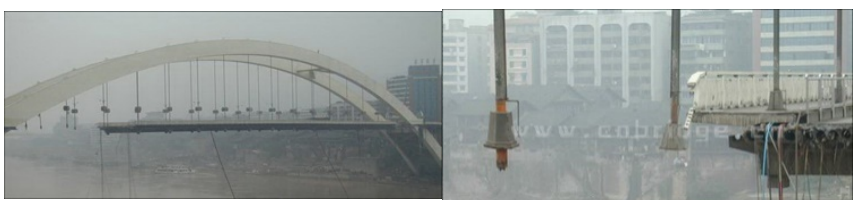

(a) Girder damaged in 2001 .

(b) Suspender corrosion

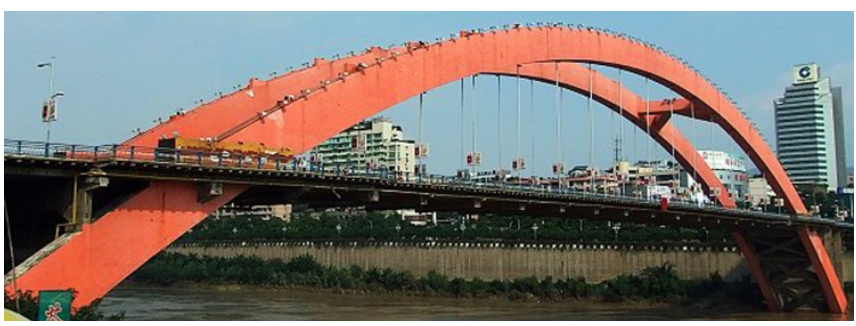

(c) Retrofitted in 2002

Fig. (8). Xiao Nan Men arch bridge in China.

\subsection{Main Results for Evaluation in Field Test Inspection}

Taking the main arch as an example, the durability indexes can be obtained based on the field testing inspection data of Xiao Nan Men Bridge:

(1) The average carbonization depth of concrete in the arch ribs is $1.94 \mathrm{~mm}$. The mean value of thickness of the protection layer of concrete in the arch ribs is $37.48 \mathrm{~mm}$. The relative carbonization depth is $0.05 \mathrm{~mm}$; 
(2) The presumed strength of concrete in the arch ribs is between $36 \mathrm{MPa}$ and $48.9 \mathrm{MPa}$, with an average of 39.64 MPa. A 0.08 deviation coefficient of concrete can be obtained;

(3) Area damage rate of concrete in the main arch is $8 \%$; thus, concrete damage rate is $8 \%$;

(4) The average width of cracks of concrete in the main arch ribs is $0.12 \mathrm{~mm}$; thus, the width of crack is $0.12 \mathrm{~mm}$;

(5) The mean value of potential levels of rib reinforced steel is $-52 \mathrm{mv}$; thus, the potential level of reinforced steel is $-52 \mathrm{mv}$;

(6) The deflection of down warp of the main arch is extremely small. The value is confirmed to be 1 through the qualitative indexes changing to the quantitative indexes.

In summary, the fuzzy membership matrix of the main arch ribs can be obtained

$$
R=\left[\begin{array}{cccc}
1 & 0 & 0 & 0 \\
1 & 0 & 0 & 0 \\
0 & 0.778 & 0.222 & 0 \\
1 & 0 & 0 & 0 \\
1 & 0 & 0 & 0 \\
1 & 0 & 0 & 0
\end{array}\right]
$$

Similarly, the fuzzy membership matrix of the influencing factors on the durability of other structural layers is listed in Table 2.

3.3. Weights of the Main Components in the Superstructure of Reinforced Concrete arch Bridge

For the weights of the main components in the superstructure of the arch bridge in study, AHP is adopted to obtain the weights of all structural layers, as shown in Table 2. The weights of the influencing factors of the durability shown in Table $\mathbf{2}$ are obtained after weight variation.

Table 2. Influencing factor of assessment on weight and durability.

\begin{tabular}{|c|c|c|c|c|c|c|c|}
\hline \multirow{2}{*}{$\begin{array}{l}\text { Structural } \\
\text { Layer }\end{array}$} & \multirow{2}{*}{ Weights } & \multirow{2}{*}{$\begin{array}{c}\text { Influencing Factors of } \\
\text { Durability }\end{array}$} & \multirow{2}{*}{$\begin{array}{c}\text { Weights of } \\
\text { Influencing Factors }\end{array}$} & \multicolumn{4}{|c|}{$\begin{array}{c}\text { Fuzzy Assessment Result on Influencing } \\
\text { Factors }\end{array}$} \\
\hline & & & & I & II & III & IV \\
\hline \multirow{5}{*}{ Main arch } & \multirow{5}{*}{0.2953} & Steel corrosion & 0.3613 & 1 & 0 & 0 & 0 \\
\hline & & Quality of concrete & 0.0838 & 1 & 0 & 0 & 0 \\
\hline & & Crack & 0.2258 & 1 & 0 & 0 & 0 \\
\hline & & Concrete damage & 0.126 & 0 & 0.778 & 0.222 & 0 \\
\hline & & Linear & 0.0469 & 1 & 0 & 0 & 0 \\
\hline Boom & 0.1407 & Boom corrosion & 0.17 & 0.85 & 0.15 & 0 & 0 \\
\hline \multirow{4}{*}{ Beam } & \multirow{4}{*}{0.0702} & Concrete carbonization & 0.2702 & 1 & 0 & 0 & 0 \\
\hline & & Quality of concrete & 0.081 & 0.4 & 0.6 & 0 & 0 \\
\hline & & Steel corrosion & 0.3264 & 1 & 0 & 0 & 0 \\
\hline & & Width of crack & 0.2159 & 1 & 0 & 0 & 0 \\
\hline \multirow{3}{*}{ Abutment } & \multirow{3}{*}{0.4236} & concrete damage & 0.098 & 0 & 0.555 & 0.445 & 0 \\
\hline & & Concrete carbonization & 0.374 & 0.5 & 0.5 & 0 & 0 \\
\hline & & Quality of concrete & 0.118 & 0 & 0.4 & 0.6 & 0 \\
\hline
\end{tabular}




\subsection{Comprehensive Durability Assessment}

The durability assessment table of the bridge can be obtained by means of the computing method of fuzzy assessment set B, as shown in Table $\mathbf{3}$.

Thus,

$B_{\text {structure }}=w * R=[0.4236,0.2953,0.1407,0.0702,0.0702] *$

$\left[\begin{array}{cccc}0.874 & 0.098 & 0.028 & 0 \\ 0.1445 & 0.0255 & 0.639 & 0.191 \\ 0.8449 & 0.0841 & 0.071 & 0 \\ 0.187 & 0.289 & 0.278 & 0.246 \\ 0.104 & 0.502 & 0.229 & 0.165\end{array}\right]$

After normalized arrangement, $B_{\text {structure }}=\left[\begin{array}{llll}0.4203, & 0.0972, & 0.2930, & 0.1895\end{array}\right]$
Based on the principle of maximum membership, the comprehensive assessment result of Xiao Nan Men Bridge is Grade I. The condition of the system durability is good; thus, the bridge can be used continuously. The result is in good agreement with the actual detection of Xiao Nan Men Bridge.

\section{CONCLUSION}

Based on AHP, this study combines fuzzy theory with AHP to establish a fuzzy AHP method, which was then used as a basis to develop a durability assessment method. Furthermore, this study adopts membership function to establish structure durability assessment model, as well as to establish the hierarchical structure for the durability of steeltube concrete arch bridge based on its characteristics and the principle of fuzzy AHP. Test data of Xiao nan men Bridge are used to analyze and evaluate the structural system

Table 3. Comprehensive grading of the durability of the whole bridge.

\begin{tabular}{|c|c|c|c|c|c|c|}
\hline \multirow{3}{*}{ Target Layer } & \multirow{2}{*}{ Structural Layers } & Modified Weight & \multicolumn{3}{|c|}{ Durability Assessment Grade } \\
\cline { 3 - 7 } & & & I & II & III & IV \\
\hline \hline \multirow{3}{*}{ The whole bridge } & Arch ribs & 0.4236 & 0.874 & 0.098 & 0.028 \\
\cline { 2 - 7 } & Suspender & 0.2953 & 0.1445 & 0.0255 & 0.639 & 0.191 \\
\cline { 2 - 7 } & Beam & 0.1407 & 0.8449 & 0.0841 & 0.071 \\
\cline { 2 - 7 } & Abutment & 0.0702 & 0.187 & 0.289 & 0.278 \\
\cline { 2 - 7 } & Accessories & 0.0702 & 0.104 & 0.502 & 0.229 & 0.165 \\
\hline
\end{tabular}

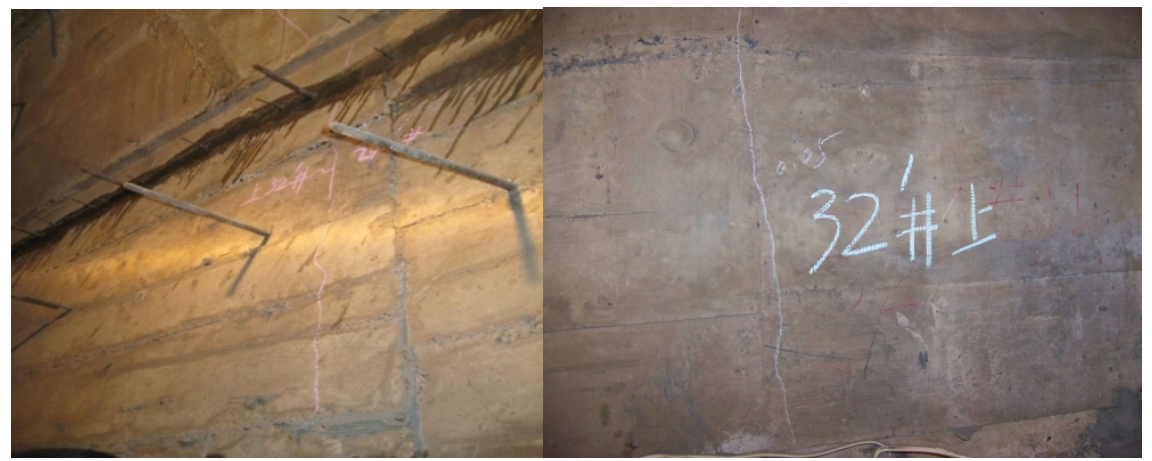

(a) Concrete cracks for arch ring
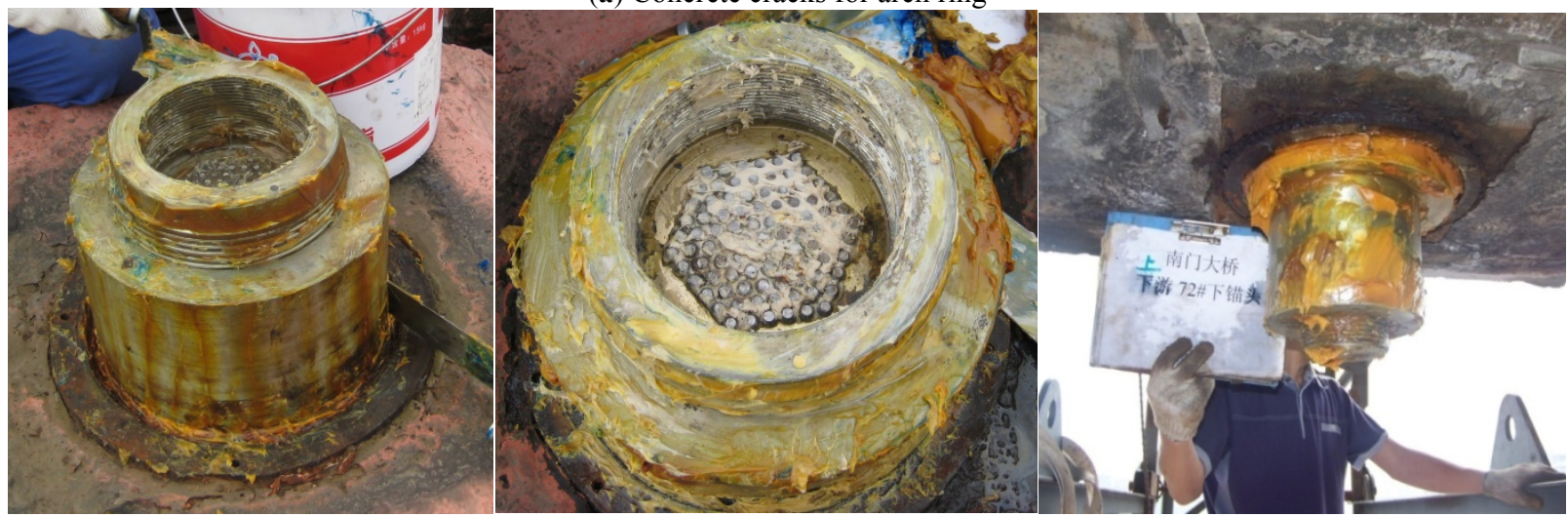

(b) Anchorage of suspender

Fig. (9). Inspection results in field test. 
theoretically. Moreover, the superstructure of Xiao Nan Men Bridge is used for durability assessment. Based on the analysis, the comprehensive assessment result of Xiao Nan Men Bridge is Grade I. The condition of the system durability is good. The assessment result is in good agreement with the actual condition of this bridge. Therefore, this method is scientifically feasible for use as an assessment tool for bridges. However, the durability assessment theory and method is not complete at the moment; further in-depth studies will be conducted.

\section{CONFLICT OF INTEREST}

The authors confirm that this article content has no conflict of interest.

\section{ACKNOWLEDGEMENTS}

The work was supported by the National Natural Science Funds for Young Scholars (No. 51408040) and the Fundamental Research Funds for Central Universities (No. 2013G1211012).

\section{REFERENCES}

[1] J.B. Ma, Q.H. Pu, and D.W. Song, "Fuzzy nearness comprehensive assessment of durability of existing half-through and through concrete arch bridges," Journal of Highway and Transportation Research and Development, vol. 25, pp. 102-108, 2008.
[2] J. D. Wei, "Urgent reinforcement and restoration of Xiao nan men bridge in Yibin city," Journal of Highway, vol. 4, pp. 34-38, 2003.

[3] P. H. Zhu, W. L. Jin, and G. R. Ni, "Durability evaluation method of reinforced concrete bridge in service," Journal of Zhejiang University, vol. 40, pp. 658-667, 2006.

[4] L. Q. Shi, C. S. Wang, and Y. Xu, "Durability assessment of reinforced concrete bridge," Journal of Highwayand Transportation Research and Development, vol. 2, pp. 112-116, 2007.

[5] ACI Committee, "Guide for revaluation of concrete structures prior to rehabilitation," ACI committee report, 364.1 R-94, 1993.

[6] F. Yang, M. B. Su, and Q. N. Li, "Calculation on weights of railway concrete girder bridges parts by several scales in the analytical hierarchy process," Journal of Xi'an University of Architecture and Technology, vol. 2, pp. 222-227, 2013.

[7] X. H. Xu, "Application of the analytical of hierarchy process in comprehensive performance evaluation of railway existing concrete bridge," Jouranl of Guizhou University of Technology, vol. 3, pp. 88-92, 2003.

[8] Z. Y. Yang, J. B. Qu, and C. K. Huang, "Bridge safety evaluation based on fuzzy synthetic evaluation method and analytic hierarchy process," Journal of Tian Jin University, vol. 12, pp.1063-1067, 2005.

[9] M. T. Liang, J. H. Wu, and C. H. Liang, "Multiple layer fuzzy evaluation for existing reinforced concrete bridges," Journal of Infrastructure Systems, vol. 4, pp. 144-159, 2001.

[10] C. Karen, and J. Y. Chou, "Safety assessment of existing structures using a filtered fuzzy relation," Structural Safety, vol. 11, pp. 173$189,1992$.

[11] A. Haldar, and R. K. Reddy, "A random fuzzy analysis of existing structures. Fuzzy Sets and Systems, vol. 48, pp. 210-210,1992.

[12] JTG/T H21. "Highway Bridge Technique Condition Evaluation Criteria, 2011.

(C) Fangwen et al.; Licensee Bentham Open.

This is an open access article licensed under the terms of the (https://creativecommons.org/licenses/by/4.0/legalcode), which permits unrestricted, noncommercial use, distribution and reproduction in any medium, provided the work is properly cited. 